\title{
Orienteering in Geography Education in Japanese High School
}

\author{
Taketo Kobayashi ${ }^{\text {a, * }}$ \\ ${ }^{a}$ Chiba Prefectural Chiba High School, Taketo_kobayashi@yahoo.co.jp \\ * Corresponding author
}

\begin{abstract}
Orienteering, a map activity, has been described as effective in learning geography in school education. When dealing with orienteering in school education, it is learning outdoors different from ordinary classroom lessons. Also, the environment surrounding school education differs from country to country. From this, it is important to show the practice of orienteering in school education in each country. In this research, I described the practice of orienteering in geography education of Japanese high schools in the following three viewpoints. The three viewpoints are the significance of orienteering in geography education, learning system of orienteering in geography education, examples of orienteering in geography education at school. The main points are as follows.
\end{abstract}

1. The skills given by orienteering are the basis of map learning and field learning in geography education.

2. Learning system of orienteering is related to the map learning and field learning perspective, such as related to the map-scale linked with place.

3. Orienteering practice in regular geography class at school grounds is the core, and good learning effect can be obtained. After this, orienteering can be expanded in a wide variety of directions.

Keywords: Geography Education, Map Learning, Field Learning, Matching the Map with the Actual Place, Orienteering

\section{Introduction}

Orienteering, with a map and compass, is a sport competing through the points shown on the map in order. It is the subject of interest in geography and cartography, because it is an activity using map. Kirby (1970) pointed out the effectiveness of orienteering in geography that includes improving the field observing ability, the map reading ability, making precise maps ability, and acquiring field research techniques. Boardman (1989) stated that orienteering can provide practice opportunities for map skills such as position, orientation, scale, terrain undulation, etc. to all people with different abilities such as age and gender. And he also suggests that people should have opportunities to learn map reading skills by orienteering at outdoor. In Japan, geographers and geographical teachers describe the effectiveness of orienteering for geography education.

There are two important aspects when implementing orienteering in school education. One is that orienteering is done outdoor. It is quite different from classroom lessons in regular school education, implementation is not easy. Another, depending on the country, the environment is different, such as the natural environment, topography and vegetation, and guidelines for learning activities. From this, it is important to describe what kind of way of thinking, how to handle orienteering, how to practice Orienteering in each country's school education.

Traditionally, in Japan, orienteering has been conducted mainly in outdoor activities of physical education in school education, and has been dealt from the viewpoint of sports rather than viewpoint of map learning. In orienteering, the map reading skills are necessary more than anything. Therefore, I will discuss orienteering from a viewpoint of geography education in Japanese high school. Specifically, it is the following three points.

- The significance of orienteering in geography education.

- The learning system of orienteering in school education (geography education).

- Orienteering practice in school education (geography education).

\section{Position of Orienteering in Geography Education}

The following three points will be described. I explain why the skills learned by orienteering are required in geography education, why orienteering is suitable as a learning method of that skill, and why the orienteering map is a suitable teaching material for learning. 


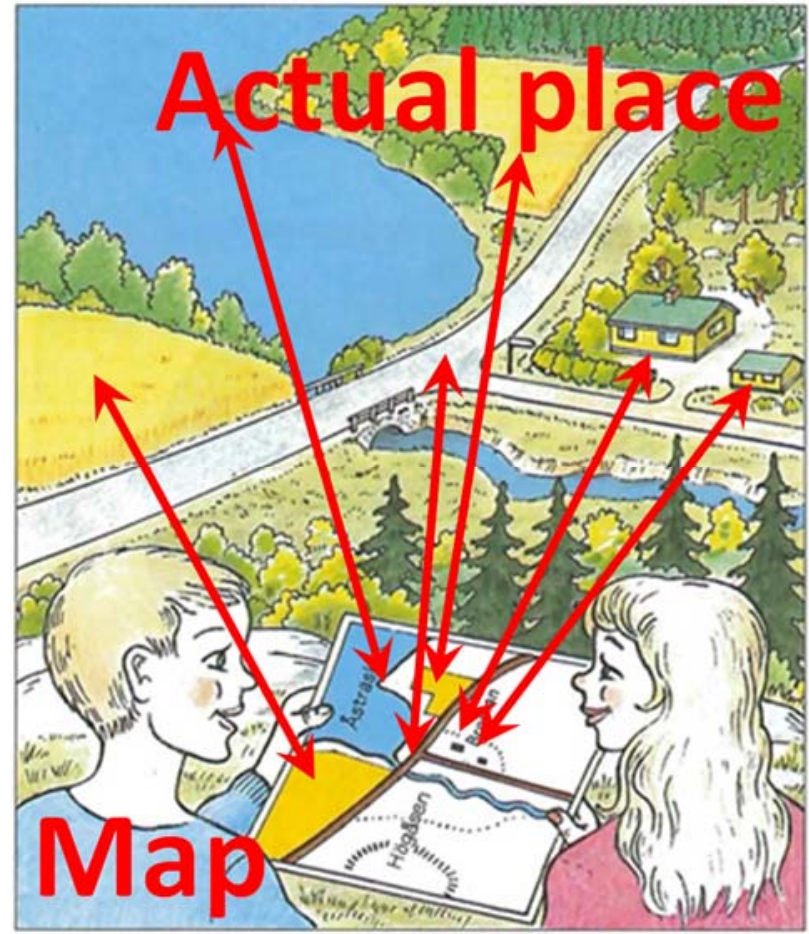

Figure 1. "matching the map with the actual place" (Lantmäteriet 1988.)

\subsection{Why is " matching the map with the actual place} " important in geography education?

What is most often done in map use is use in navigation. This skill is used on a daily basis. It is also used for recreation such as town walking, sightseeing, hiking, mountain climbing, and evacuation in natural disasters. The basis of this skill is to compare the situation expressed on the map with the situation of the site, that is, "matching the map with the actual place" (Figure 1). When applying this skill to geography education, it is positioned as a basic skill in both maps reading ability from the viewpoint of map learning and field observation ability from viewpoint of field learning. It is necessary to comprehend the map with the real landscape in order to understand not only the navigation, but also the learning large-scale map. The skills, which is " matching the map with the actual place ", promotes spatial awareness and understanding of the region. It is necessary for geography learning to need to proceed this skill. For example, in order to obtain disaster risk in the area in advance, it is necessary to capture the area spatially. And for that purpose, it is important to comprehend the large-scale map indicated the disaster risk with the actual landscape.

2.2 What kind of learning method is effective for learning " matching the map with the actual place "?

Normally at school education, it is standard that one teacher teaches 40 learners in the classroom. Learning " matching the map with the actual place " is done outdoors. It is not easy to prepare scenes of learning outdoors. For example, at outdoor field, it is difficult for one teacher to explain to 40 students. It is desirable to have a mechanism that enables individual learners to learn individually with a map at outdoor field.

Orienteering, with map and compass, is a sport that competes navigation. Doing this is to do navigation skills. When the learner performs orienteering, the learner is sent to the point indicated on the map. Since the control marker is set up on the actual point, if reaching there, correct answer can be obtained. By doing orienteering, learning of navigation with a map is automatically directed, and " matching the map with the actual place " is promoted in the process. Orienteering is an effective learning for " matching the map with the actual place " (Kobayashi 2014).

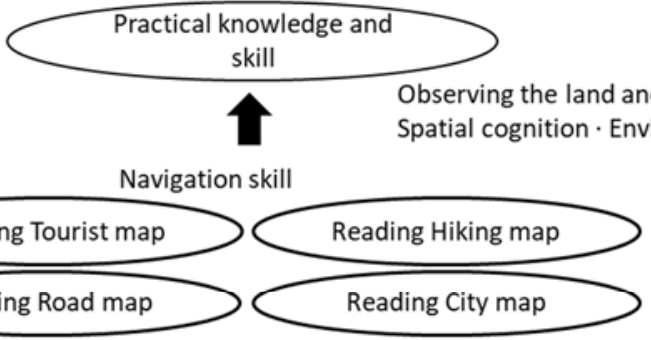

Daily practical use of map
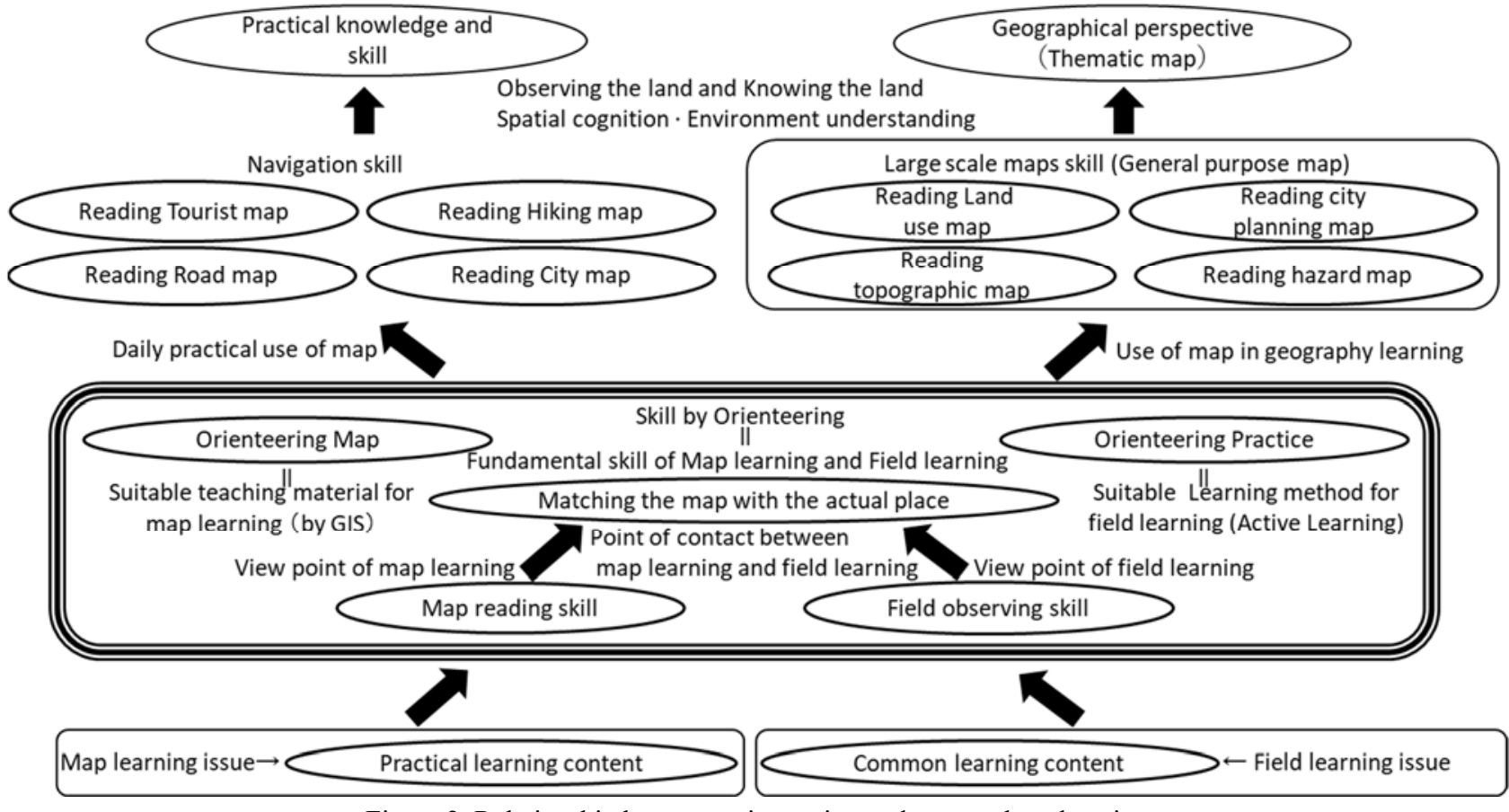

Figure 2. Relationship between orienteering and geography education 
Table 1. View point from McNeill's Orienteering lesson plan

\begin{tabular}{|c|c|c|c|c|c|c|c|}
\hline & & & & KeyStage1 & KeyStage2 & KeyStage3 & KeyStage4 \\
\hline map & scale & Place & $\begin{array}{l}\text { easy } \\
\text { /difficult }\end{array}$ & $\begin{array}{l}\text { elementary } \\
\text { school/low }\end{array}$ & $\begin{array}{l}\text { elementary } \\
\text { school/high }\end{array}$ & $\begin{array}{c}\text { junior high } \\
\text { school }\end{array}$ & High school \\
\hline map & $1: 100$ & Classroom & easy & O & O & & \\
\hline map & $1: 500$ & $\begin{array}{c}\text { Gymnasium/ } \\
\text { Hall }\end{array}$ & $\uparrow$ & 0 & 0 & $\Delta$ & \\
\hline map & $1: 500$ & Playground & & $\mathrm{O}$ & O & $\triangle$ & \\
\hline $\begin{array}{l}\text { O-map } \\
\text { (issom) }\end{array}$ & $1: 1000 \sim 1: 2000$ & $\begin{array}{l}\text { School } \\
\text { Ground }\end{array}$ & & $\Delta$ & $\mathrm{O}$ & $\mathrm{O}$ & $\mathrm{O}$ \\
\hline $\begin{array}{l}\text { O-map } \\
\text { (issom) }\end{array}$ & $1: 3000 \sim 1: 5000$ & Park & & & 0 & 0 & 0 \\
\hline $\begin{array}{l}\text { O-map } \\
\text { (issom) }\end{array}$ & $1: 4000 \sim 1: 10000$ & Woodland & $\downarrow$ & & $\Delta$ & 0 & 0 \\
\hline $\begin{array}{l}\text { O-map } \\
\text { (isom) }\end{array}$ & $1: 7500 \sim 1: 15000$ & Forest & difficult & & & $\Delta$ & 0 \\
\hline
\end{tabular}

2.3 Why is the Orienteering map suitable for learning " matching the map with the actual place"?

Orienteering is a sports competition, so fairness is required. Regulation rules have been established, maps are also negotiated in the rules of competition. Orienteering uses the map dedicated to this. This is a view that does not be seen in other map-based sports (such as Rogaining, Mountain Marathon). Orienteering map is made from the point of view of the competitor. (Zentai 2014). It is suitable for " matching the map with the actual place ". Preparing and using a suitable map for the purpose leads to effective learning. The reason why the map is defined in the rules of competition is because of to hold international competitions. This is because it is not fair to compete in the using topographic maps which are different from country to country. Orienteering map expresses various environments around the world under uniform specification. By reading this map, versatile map skills will be obtained.

Implementing orienteering by geographical learning is effective in two ways as an activity for learning of " matching the map with the actual place " and as a teaching material supporting that learning (Figure 2).

\section{Learning system for orienteering in school education}

When dealing with orienteering from the viewpoint of education, it is necessary to consider the ordering of learning based on 'from easy to difficult' etc. Therefore, the learning system will be described.

\subsection{What is the Orienteering learning system?}

Various skills are required for orienteering competitions. It can be roughly divided into map reading skills and moving skills. The moving skills have a long-range running endurance, a technique that runs ascent and descent, etc. However, no matter how this skills are, it is impossible to reach the designated place without ability of reading map. Map reading skills are more important than anything in orienteering. It is necessary to indicate
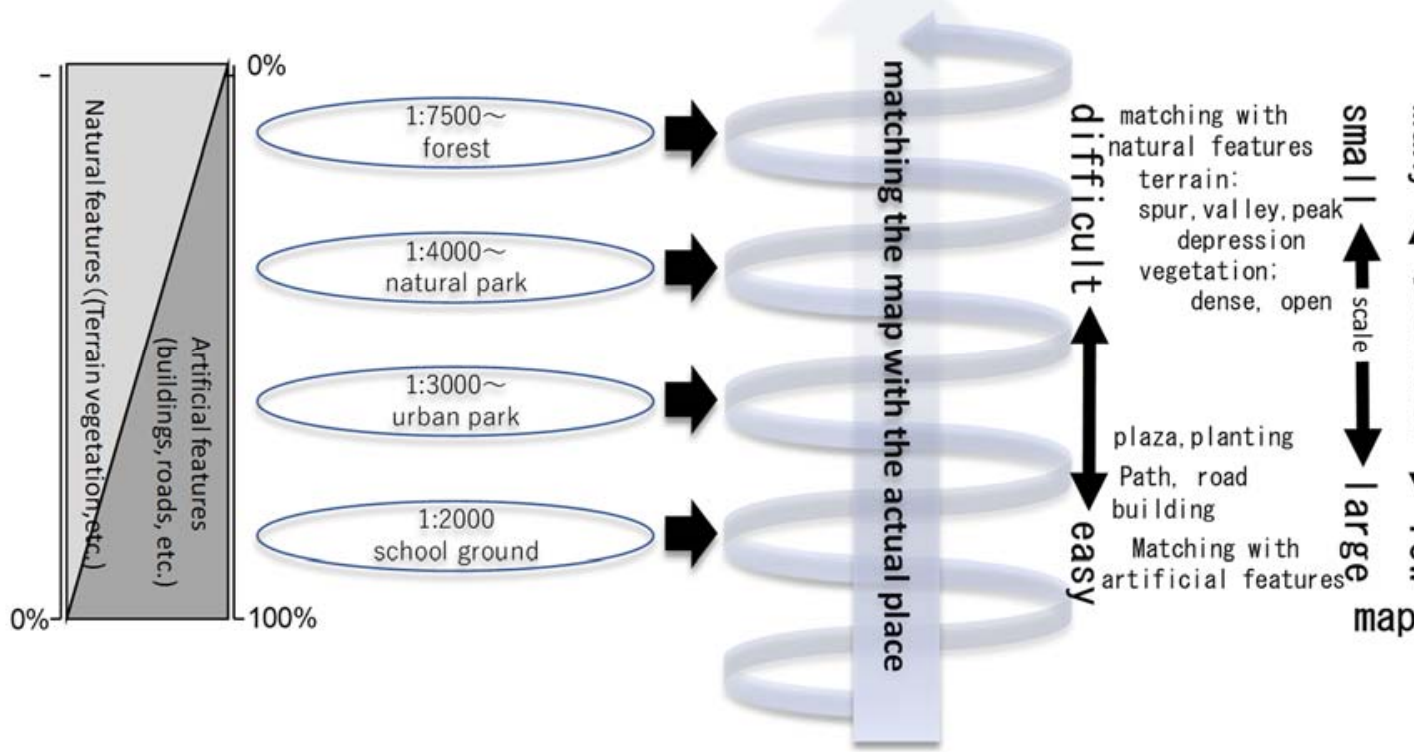

Figure 3. Relationship between Orienteering Map and practical place in "matching the map with the actual place" skill 

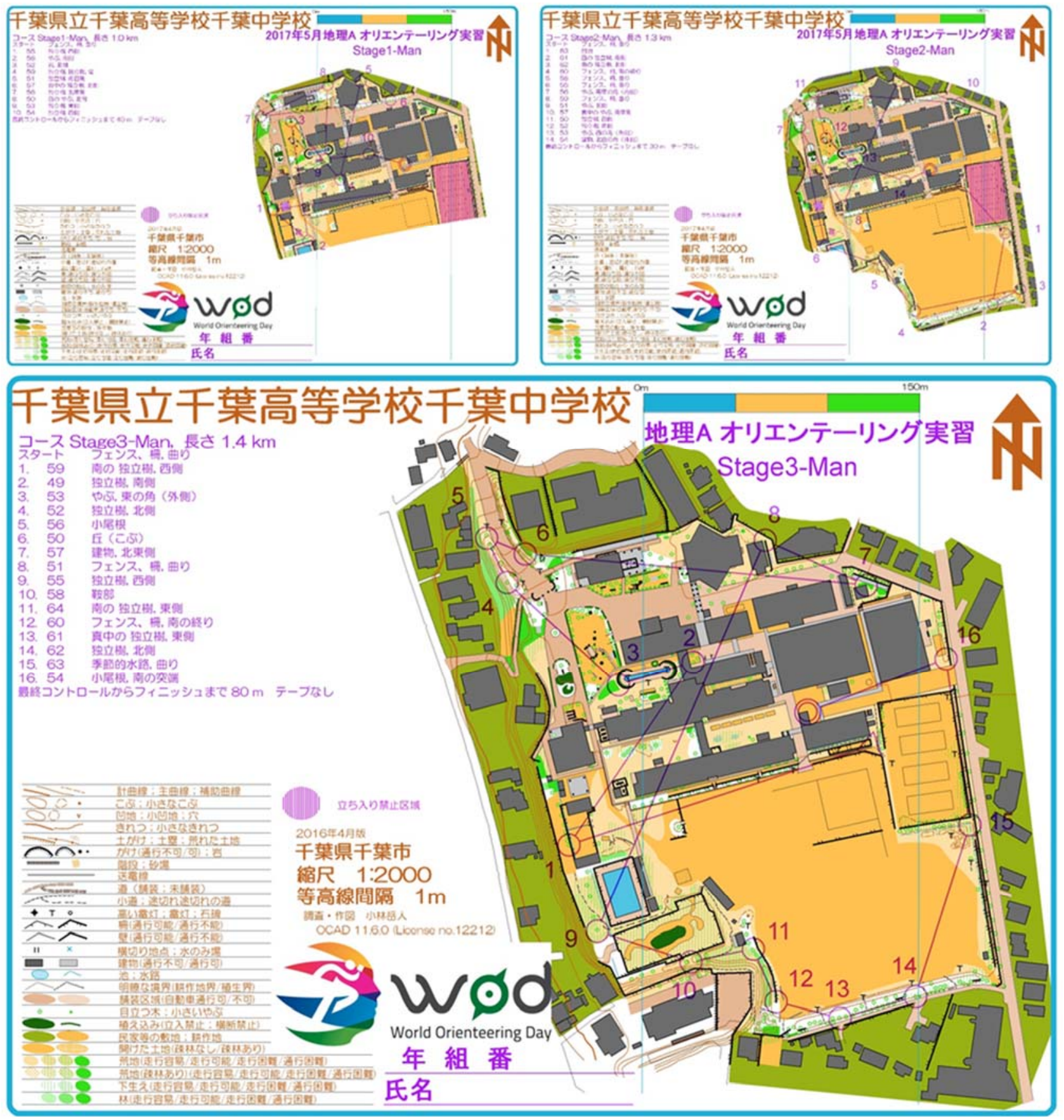

Figure 4. School ground Orienteering Map "Chiba Prefectural Chiba High School"

Upper left is stage1 (short and easy), Upper right is stage2, Lower is stage3 (long and difficult).

the learning system from the viewpoint of map learning.

McNeill and Martland and Palmer (2003), McNeill and Palmer (2005) have been developed lots of lesson plans to carry out orienteering in school education of K12 (elementary school to senior high school). From this lesson plan, two perspectives, course setting and lesson place, are found about difficulty-easiness. From the viewpoint of map reading, it is possible to set difficulty by course setting such as control position and number, complexity of route plan, presence / absence of route choice, etc. However, on the same place, the same map, there is a limit to the difficulty setting by course setting.
Table 1 summarizes the place of implementation from the lesson plan of McNeill $(2003,2005)$ and others.

Lesson at the school ground is the core part of orienteering practice in school education. Orienteering at school ground is "goal" at elementary school, "intermediate goal" at junior high school and "introductory" at high school. At the high school level, after the school ground, orienteering lesson is carried out while changing places in the order of urban park, nature park, woodland and forest. That is a change from a known near place to an unknown distant place. The place and the scale are related, and the scale of the map gradually decreases. Local features will be omitted by 


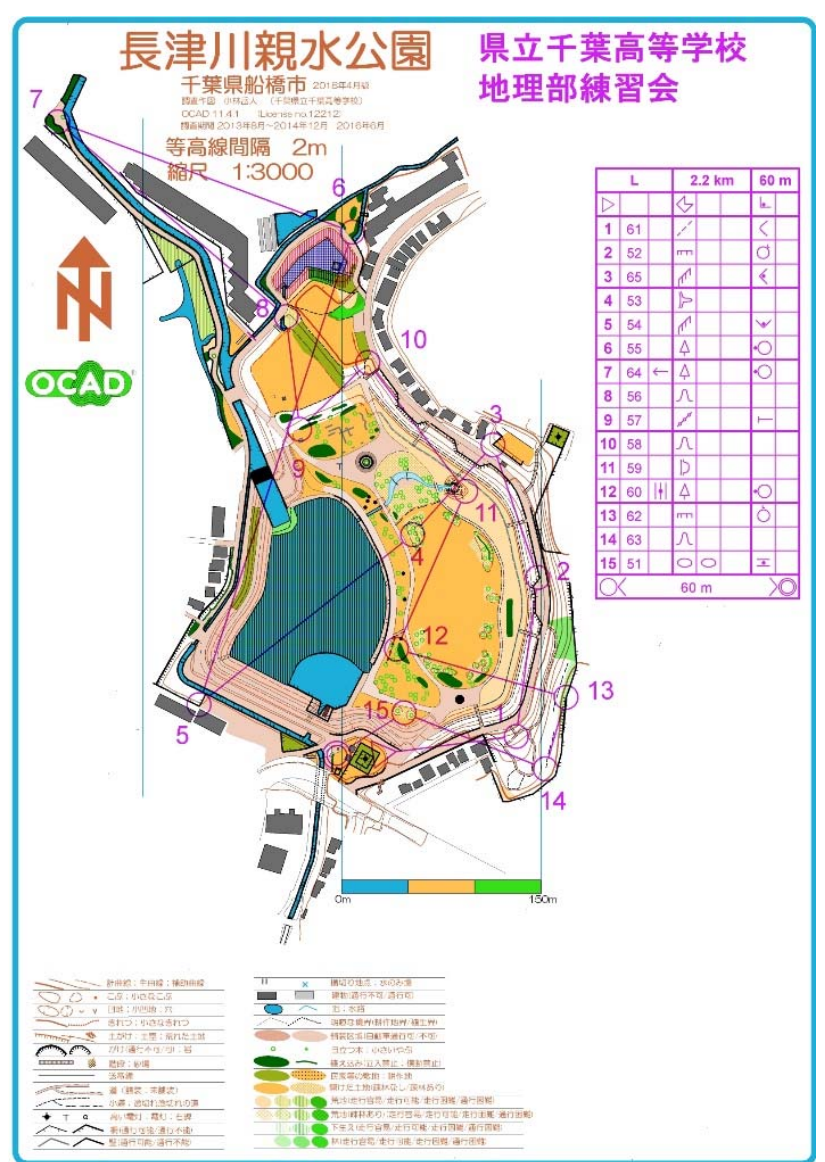

Figure 5. Urban park Orienteering Map "Nagatsu river water front park"

Cartographic generalization. As changing from school ground to forest, the environment changes from artificial objects to natural objects. Natural objects like terrain and vegetation are not clearer than artificial objects like roads and buildings. The terrain is expressed by contour lines. " matching the map with the actual place " skill becomes difficult. This series of systems is consistent with the point of view of map learning and outdoor learning.

By systematically providing the course setting and execution place, map reading ability and field observation ability of the learner will be improved.

\subsection{What is the orienteering learning system at the high school in Japan?}

Based on the above, I considered the learning system in Japanese high school (Figure 3). First of all, it is orienteering on the familiar school ground. Orienteering map (O-Map) was created with a large scale of 1: 2000 (Figure 4). With this scale, almost all the local features are represented on the map. " matching the map with the actual place " should be able to do anywhere if you see the map firmly. For Orienteering here, anyone can do it simply by saying "Please see the map and go around in order". The course setting can vary the difficulty. Figure 4 has three maps. Upper left is short and easy, upper right is middle and modest, lower is long and tough. And the next stage is urban park (neighborhood park). O-Map with scale 1: 3000 was created (Figure 5). Neighbohood parks are strange places. Using the compass, explain how to align the direction of the map with the direction of the site by compass (setting the map with a compass). This makes it easy to " matching the map with the actual place ". If orienteering at the school ground is experienced, it is possible to orienteering well enough by adding this explanation. And the next stage is a natural park. O-Map with scale 1: 4000 was created (Figure 6). Natural parks also involve the expression of terrain on contour lines. It is necessary to how to read the contours such as ridge and valley. After explaining the ridge and valley, the practical course is challenged. Orienteering competitions are often held in the field of forest as $\mathrm{O}$ - Map with a scale of 1: 10000 to 1: 15000 . This is a map (ISOM) different from the sprint type map (ISSOM) that we have dealt with so far. So, we created an O-Map with a scale of 1: 10000 in the same natural park (Figure 7). At this stage, pace counting is explained.

The process, school ground (1: 2000) $\rightarrow$ neighborhood park (1: 3000) $\rightarrow$ natural park (1: 4000, 1: 100000), is a possible anywhere in Japan. By doing at school ground and park, safety of students is also secured. The lessons conducted while changing place and map scale are consistent with the basic technical guidance of orienteering. By taking these steps, the skill of " matching the map with the actual place " improves.

\section{Example of orienteering in school education (geography education).}

An example of orienteering in school education (geography education) will be described based on Chapter 2 and Chapter 3.

\subsection{How can Orienteering practice at school education?}

Even orienteering at school ground, it is the first experience for learners to use map that is expressed precisely. They may get lost even though it is familiar like school ground, because of it is required to read the map finely. That is why " matching the map with the actual place " is not done properly. Reading map finely is not tried, so appropriate information has not been pulled out from the map. By experiencing orienteering, learners will notice this. Learner can obtain this "awareness" sufficiently even at the school ground. This "awareness" is the foundation of map learning and field learning. And, if you do not understand this "awareness", all subsequent geography learning will be delayed

Using orienteering map of the school ground (Figure4 1: 2000 ), orienteering was carried out as follows. In the 50minute class of 40 students on the school ground, the course was set to about 10 minutes for the top person and about 20 minutes for the lower level persons. Three lessons were made to establish the skills. The first stage (Figure 4 upper left), the course is short and no route choice $(0.9 \mathrm{~km} ; 11$ control). Control points locate near school buildings. Using area is only school building site. The second stage (Figure 4 upper right), the course is somewhat longer and route plan is slightly complicated (1.2 km; 11 control). Control points use also vegetation. Using area include school ground, too. The third stage 


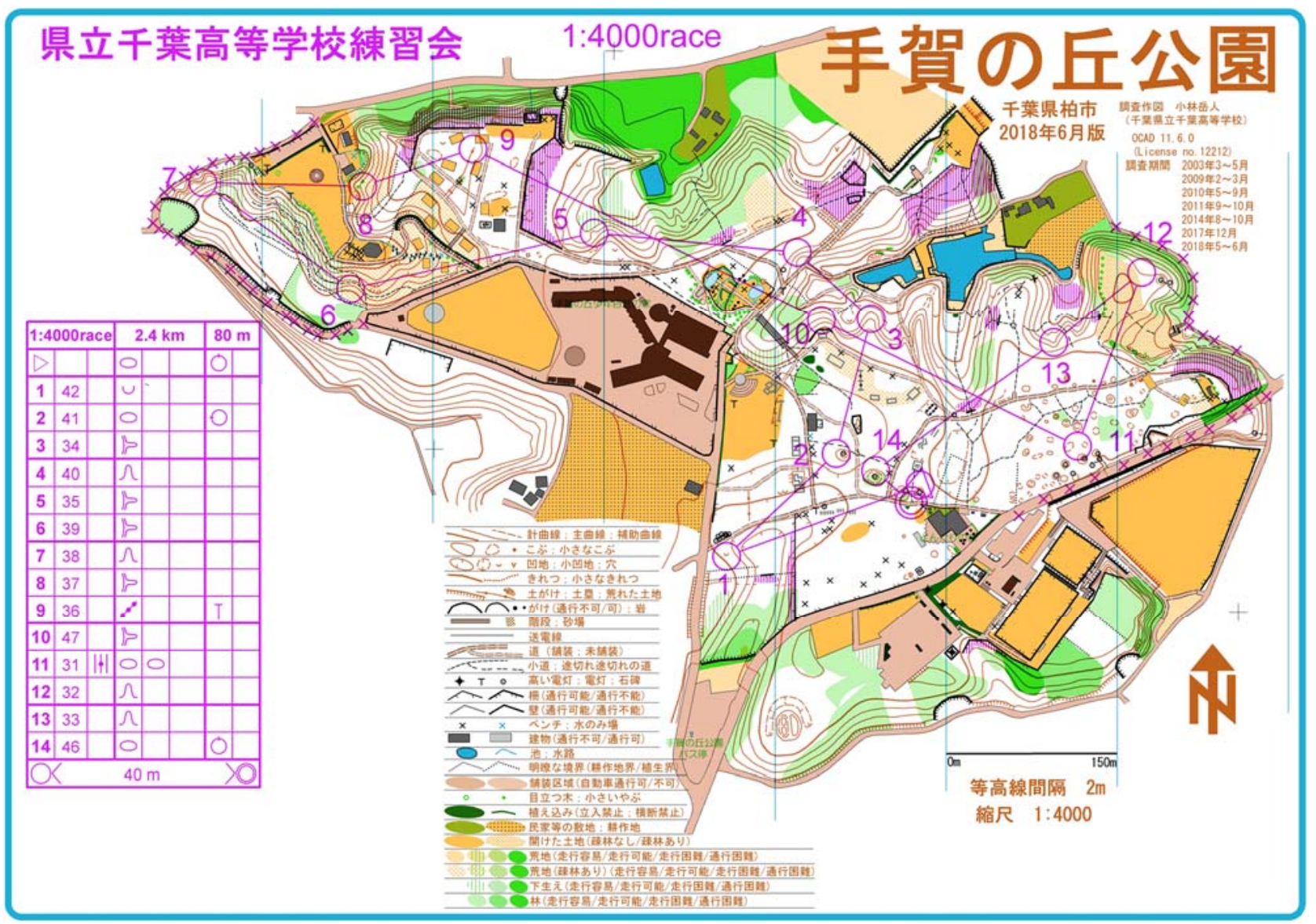

Figure 6. Natural park Orienteering Map "Tega hill park"

(Figure 4 lower), each section in the course has multiple route $(1.4 \mathrm{~km} ; 16$ control $)$. Control points use topographical features, dense vegetation etc., too. Using area is all school site. This was done for all 320 students in the entire grade.

What is optimized for competing navigation skills using maps is the orienteering competition format. For this reason, practicing in the lesson also follows the competition format, so that learning is done more efficiently. Competition requires seriousness by learners. Measuring competition time will encourage learners to turn as fast as possible. Time difference start requires individual learner to individual play and individual

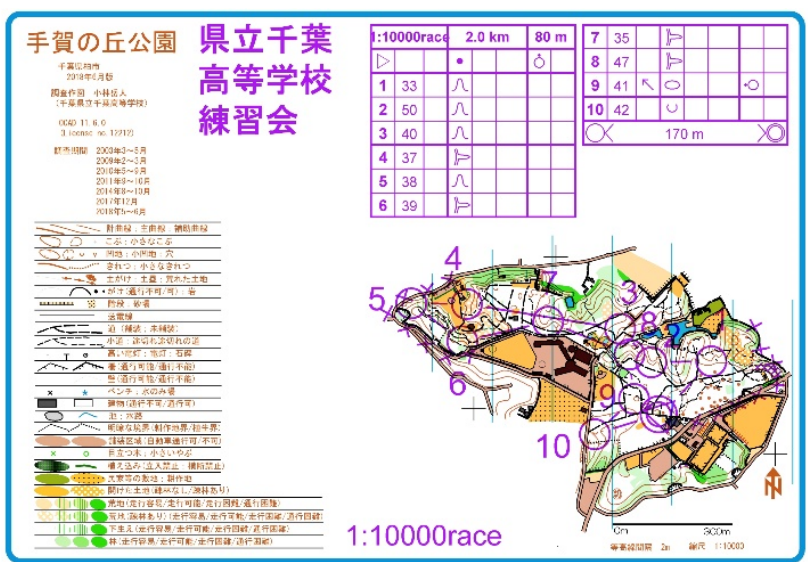

Figure7. Natural park Orienteering Map (forest type map) "Tega hill park" judgment. And, using orienteering map specialized for navigation brings effective map reading learning. As soon as finishing, the learner receives quick feedback by dedicated timekeeping system printing the result including the time required between each control.

Orienteering on the school ground becomes the basis of each of map learning and field learning. Learners learn ingenuity such as setting the map with a compass, and they can see what kind of things the map symbols actually show on the site. Learners can refine spatial grasping ability and sense of direction and know how to move with a map. Learners will learn the environment of the school as if the school is located in what kind of terrain, and will draw interest in the land itself. These are the learning of geography itself. I got the following comments from students who experienced three orienteering exercises at the school ground. After the first stage, that "it is necessary to read the map well" was mentioned. After the second stage, "Impressive improvement in map reading ability" "Balance between reading and running speed is necessary" " matching the map with the actual place ". After the third stage, "Good experience" "Sense of accomplishment" "I want to try in earnest in the forest" "Application to life" "How can you use it in an unknown place" "Knowledge for the time of disaster". The method of making use of the map reading skills obtained here was stated. Most of the students felt it was fun each time (Kobayashi 2013). The effect obtained by orienteering on the school ground is remarkable. 


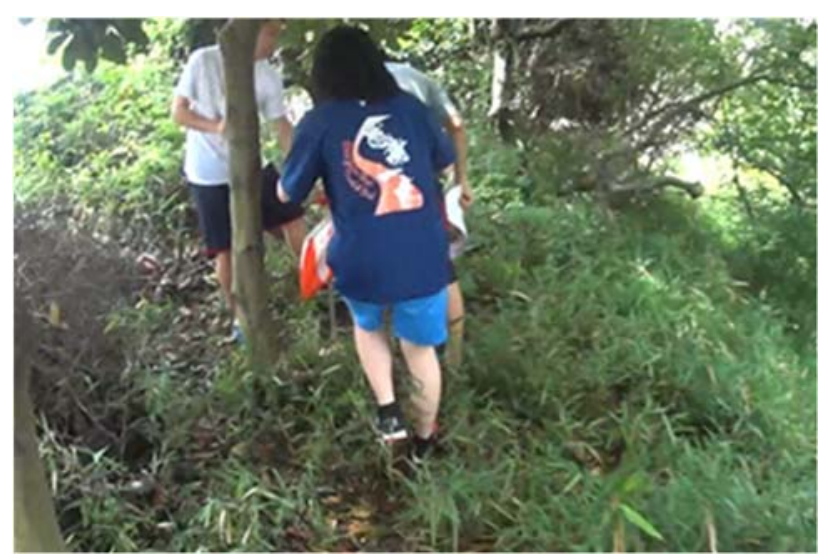

Figure 8. Orienteering practice at school ground "Chiba Prefectural Chiba High School"

\subsection{How can Orienteering lessons be held outside the school?}

It will be difficult to implement within the lesson time to do orienteering outside the school. It is necessary to set the time again. For example, in the idea of so-called curriculum management, it is required learning activities outside the school such as school excursions. etc. However, by implementing it in club activities, after school, weekends, long holidays, can be set. First of all, about 30 students with interest in orienteering on the school ground played orienteering at a neighborhood park for about half a day (Figure 5, Figure 9). Students were already experiencing orienteering on the school ground, so they were less confused. In addition to the club activities (geography club etc.) that make orienteering one of the activities, it is also possible to call for participation in activities as part of physical fitness training for track and field, tennis, swimming, etc, as part of map reading training for wandervogel etc. Next, orienteering was carried out for about 10 students in club activities whose orienteering is the main activity in a natural park a little far away on a holiday (Figure 6). In addition, we also used the orienteering map of 1: 10000 created in the same park so that it was practicing to participate in the actual orienteering competition (Figure 7).

By experiencing orienteering at various scales and environments like this, map reading skills is improved. It is effective for map learning and it will be possible to actually participate in orienteering competitions as well.

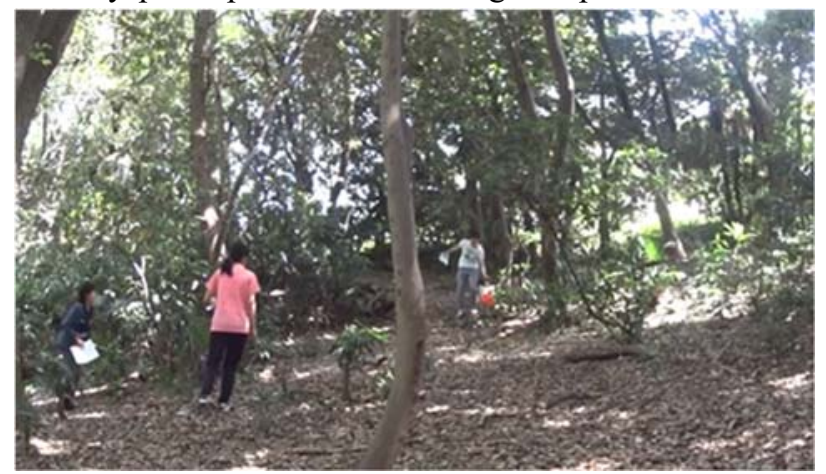

Figure 9. Orienteering practice at urban park "Nagatsu river water front park"
Participation in the competition event is also similar. It is effective to participate by the step by step in the competition in the neighborhood park, the competition in the natural park, the competition in the forest.

\subsection{What is the significance of holding the orienteering competition?}

Orienteering to do outdoors using a map consists of various elements. It is not easy to set up the orienteering competition field at outdoor. Making places for orienteering competitions brings about various effects in education. Orienteering is usually done by one person, but the setting of such a scene is created by some

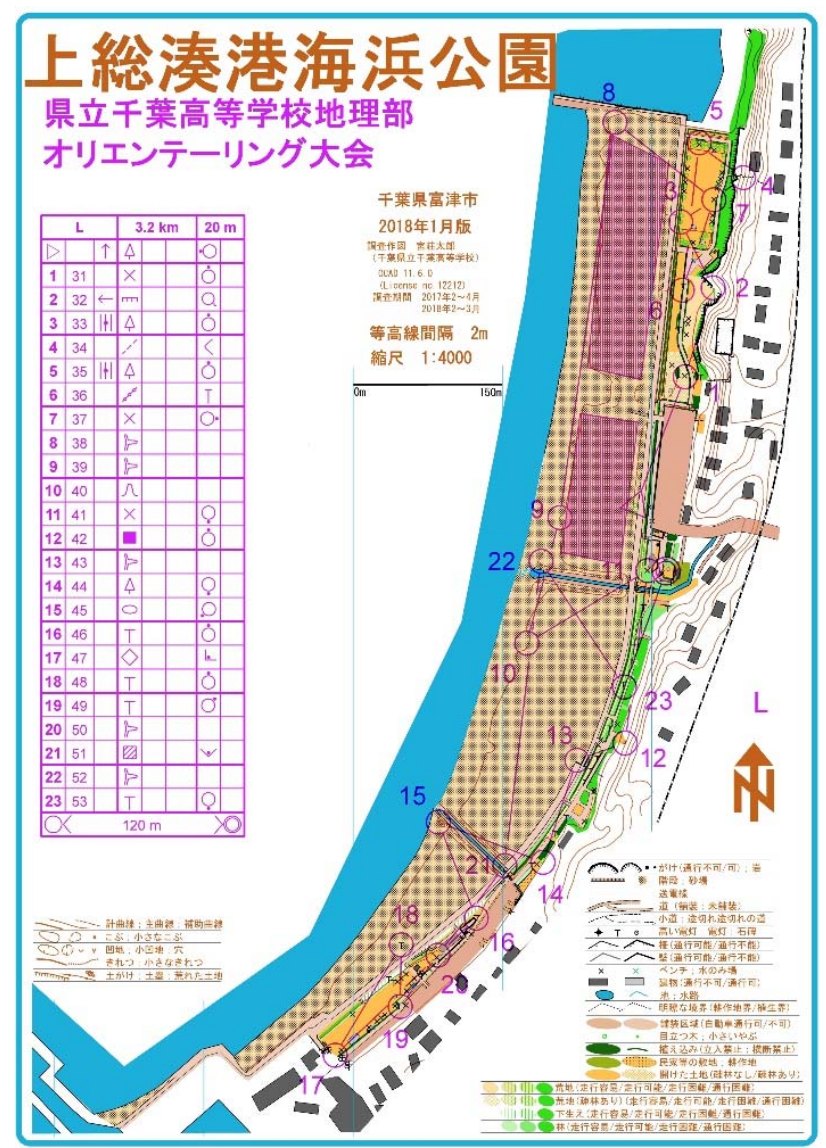

Figure 10. Orienteering Map by student making "Kazusaminato port park"

cooperation.

Figure.10 is the orienteering map at the park of a depopulated area created by one of the students in the geography club. Using this, we held an orienteering event with about 10 students. Orienteering is done outdoors, so it ties closely with the land. It will inevitably be an activity in the relationship with the local community. Holding events in areas with decline population and aging population will bring about regional revitalization. In addition, orienteering is to read the state of the land through the map, doing the Orienteering itself will inevitably experience the state of the land. Participants gathered will have a strong impression of the area. Making orienteering maps will add great value to the land. This will be effective from the viewpoint of land use. Regional learning is important in geography learning. 
Regional contribution activities is a very important. There are various forms of regional contribution activities, but holding events is easy to understand as a form. And since the content of the event is an activity with a map, it is suitable for geography education.

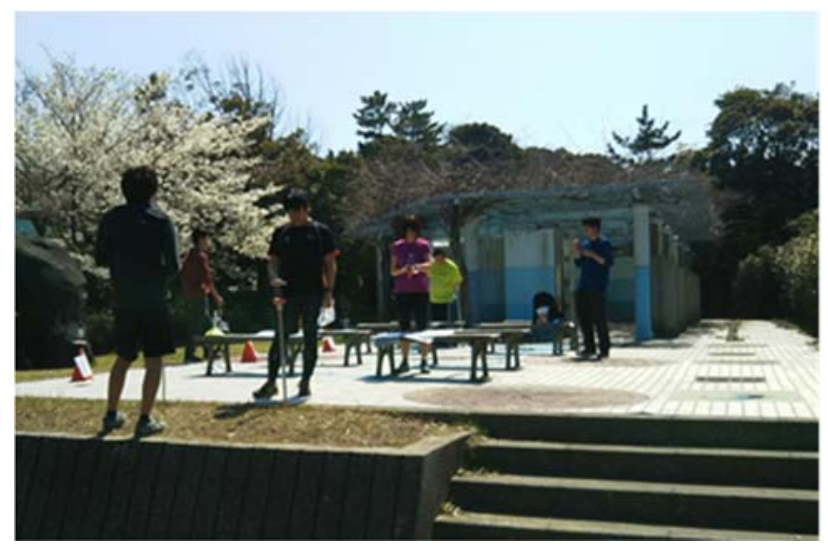

Figure 11. Organizing Orienteering event by students "Kazusaminato port park"

\section{Conclusions, Challenges, Perspectives}

Orienteering brings basic skills in learning geography and it is positioned as an introduction of generic and practical geographical skills. Furthermore, it is a learning activity with a subjective experience. And it brings the skills that are necessary from the viewpoint of social independence. Indeed, it is the geographical skills that live and work. This skill is required for all activities outside the school such as school excursions and accommodation training. At that time, orienteering practice at the school ground will be pre-learning activities outside the school. Furthermore, it is also possible to utilize from the point of view of a cross curriculum. For students who are interested, there is also a direction of participating in the orienteering competition in the framework of club activities.

However, when practicing in school education (geography education), there are many problems such as teaching skills of the professor side, acquisition of orienteering map which is teaching material, special equipment for timekeeping measurement, etc. These are essential for effective learning. To that end, we think that it is necessary to create a system that can be supported by orienteering experts to the educational site.

The opportunities to use the map are increasing by the progress of geographical information technology in recent years. Using map requires of map reading skills. The skill, which is "Matching the map with the actual place ", is necessary skill required anytime, anywhere. Since, globalization is progressing in today's society, there are many opportunities to go abroad. To adapt to unfamiliar land and unfamiliar environments, this skill is very effective. Sediment disasters and floods caused by earthquakes and typhoons, heavy rains occur in various places such as The Great East Japan Earthquake. Living in response to these natural disasters is required. For all people living here, this skill is an indispensable life skill.
The skills, which is " matching the map with the actual place ", promotes spatial awareness and understanding of the region. Since most of students are urban residents and mainly living in the urban environment. They are not familiar the rural environment and landscape. Normally, orienteering event are held in woodland or forest which is located in the so-called rural area. By taking part in orienteering event, they will concern for rural issues such as depopulation and declining birth-rate and aging population. By experiencing orienteering on the distinctive land, it will be interest to the land. For example, if participating in orienteering events in distinctive terrain such as sand dunes at Kujukurihama coast and in caldera on Izu Oshima island, it will be a good chance of learning of the terrain.

The possibility of carrying out orienteering in school education (geography education) is exhausted. Regarding Orienteering, which is a valuable activity utilizing maps, handling from the viewpoint of geography education is also effective in attracting interest in geography education.

\section{References}

Boardman, D. (1989). The Development of Graphicacy : Children's Understanding of Maps. Geography, 74-4, 321-331.

Kobayashi, T. (2013). Study about navigation in the high school geography education. - Practice of orienteering competition in class - . The Academic Meeting of the Association of Japanese Geographers Spring 2013. (General Presentation (oral presentation))

Kobayashi, T. (2014). Study about training of orienteering in the high school geography lesson and the effect. The Academic Meeting of the Association of Japanese Geographers Spring 2014. (General Presentation (oral presentation))

Kobayashi, T. (2017). Study systematization of Orienteering learning from view of geography learning. The Academic Meeting of the Association of Japanese Geographers Spring 2017. (General Presentation (oral presentation))

Kirby, R. P. (1970). The Geographical Sport of Orienteering. Geography, 55-3, 285-288.

\section{Lantmäteriet. (1988). KARTLÄROBOKEN.} Lantmäteriet. $48 \mathrm{p}$.

McNeill, C. and Martland, J. and Palmer, P. (2003). Orienteering in the National Curriculum: Key Stages 1 to 3. Harvey Map Services Ltd. 80p.

McNeill, C. and Palmer, P. (2005). Orienteering in the National Curriculum: Key Stages 3 and 4 . Harvey Map Services Ltd. 80p.

Zentai, L. (2014). Orienteering And for finding the cache. ICA The IMY Working Group (2014). The World of Maps. Chapter12, 1-5. 